\title{
The Virtuous Circle of Omnichannel CRM
}

Author 1: Dr David Cattrall, Independent Researcher (dave@bss-refresh.co.uk). A UK-based former academic who has published papers on digital marketing and data management. dave@bss-refresh.co.uk; www.bss-refresh.co.uk; www.linkedin.com/in/davidcattrall/

Corresponding Author 2: Dr Simone Castello, Independent Researcher (sc780@cam.ac.uk) An independent researcher working at the University of Cambridge in marketing and communications; www.linkedin.com/in/simonecastellodigitalstrategy/

We declare no conflict of interest. Although we gave examples of business practices, we do not endorse any software, company nor program.

\begin{abstract}
This paper extends previous research on the influence of social media and digital channels on customer purchase behaviour by presenting a new omnichannel purchasing model. We characterise that model as a "virtuous circle" as it centres around customer use of social media and has potential to benefit both customers and companies. We illustrate that model with a worked example, discuss approaches to its implementation and evaluate its use in the context of a business case study. The model creates a framework that combines elements of digital marketing, social CRM, omnichannel CRM, and customer experience and engagement. This paper bridges academic and industry practitioner communities across those fields.
\end{abstract}

Keywords: digital marketing; social CRM; omnichannel CRM; customer experience management; customer engagement; marketing automation; B2B / B2C marketing

\section{Introduction}

The influence of social media and digital channels on customer purchase behaviour within omnichannel retailing has been widely discussed in academic literature. In their framework for digital marketing research, Kannan and Li (2017) note the importance of "understanding how buyer behaviour is affected by stages of buying process, purchase funnel and impact of digital environments and digital devices”. More recently, the Marketing Science Institute's research priorities for 2020-22 include the topic, "Strategies to prioritize customer value at all touchpoints during the omnichannel customer journey", asking the questions: How does the increasingly complex technological, promotional and advertising ecosystem affect the customer journey? What are the most effective strategies to driver deeper, lasting customer engagement/loyalty with the firm? A second topic, "Managing brand experience and 
promotion across the customer journey" raises the question: How does omnichannel retailing interact with the purchase funnel? (MSI 2020). In this paper, we aim to provide some further insight into those topics and potential answers to those questions.

Section 2 reviews the social media, digital marketing, social CRM, omnichannel CRM and customer experience/engagement academic literature. Combining and extending that research, section 3 presents a new omnichannel purchasing model, the "virtuous circle", discussing a worked example of its use and approaches to implementation. Section 4 presents a real business case study. Section 5 provides conclusions and implications for academic research and industry practitioners. Section 6 identifies limitations and areas for future research.

\section{Theoretical Framework and Literature Review}

\subsection{Social Media, Customers and Brands}

From a practical/technical perspective, social media can be defined as a collection of web 2.0 applications providing the creation and exchange of user-generated content (UGC), while facilitating interaction and collaboration between participants (Kaplan and Haenlein, 2010). Applications include blogs and microblogs (e.g. Twitter), social networking sites (e.g. Facebook), virtual worlds (e.g. Second Life), collaborative projects (e.g. Wikipedia), content community sites (e.g. YouTube, Flickr), online communities, e-commerce and professional review sites (e.g. Amazon) (Voramontri and Klieb 2018; Appel et al. 2020; Alves et al. 2016; Leek et al. 2016). From a wider, sociological perspective, social media can be considered as digital places where people conduct significant parts of their lives and it concerns what people do in those environments (Appel et al. 2020).

Social media sites provide means for users to interact with content about anything, including brands. Indeed, B2C and B2B (business to consumer and business to business) marketing practitioners take advantage of the interactivity of social media channels to set up communities in order to foster engagement with products and brands.

Muntinga et al. (2011) categorise user-brand activities on a continuum from low to high, in three dimensions: consuming (viewing and reading content), contributing (rating products, commenting in conversations) and creating (writing reviews, uploading videos). Those activities are driven by underlying user motivations and behaviours that researchers have attempted to classify. Common classifications include knowledge learning, influencing others through social interaction, and supporting the firm as a brand advocate or by contributing to product development (Muntinga et al. 2011; Brodie et al. 2013; Schau et al. 2009). Moreover, those interactions may contribute to value cocreation benefiting customers and the firm 
(Alexander and Jaakkola 2015; Jaakkola and Alexander, 2014). The most successful brand communities continuously evolve and marketing managers may wish to create and nurture participatory customer base by accumulating knowledge about consumer behaviour in social media brand communities (Schau et al. 2009; Kamboj et al. 2018).

Information sharing is referred to as (online or electronic) word of mouth (WOM) (HennigThurau et al. 2004). WOM occurs when consumers provide reviews and ratings to products, brands and services on social media sites and the material disseminated is rarely available through company-led marketing communications (Bronner and de Hoog, 2010). WOM is a primary source of information impacting all phases of consumer decision-making, shaping perceptions and expectations of brands, from product awareness to selection and postpurchase evaluation (Kimmel and Kitchen, 2014; Voramontri and Klieb 2018). Appel et al. (2020) note the rise of "micro-influencers". These individuals are often seen as credible experts, encouraging others to want to view the content they post and engage with them. Considering the possible reach and engagement influencers command, companies have begun embracing them on social media.

Malthouse and colleagues demonstrate that prompting consumers to create UGC that elaborates on a personal goal that is relevant to a brand affects buying decisions causing higher levels of purchases (Malthouse et al. 2016a; Malthouse et al. 2016b). Similarly, for online brand communities, motivating users to participate in user-centric innovation activities by creating a meaningful experience, increasing the level of playfulness, and helping young users to enhance their status can all stimulate participation (Kaur et al. 2018).

Burmann (2010) introduces the term User-Generated Branding (UGB) as, "the strategic and operative management of brand related UGC to achieve brand goals". UGB includes all voluntarily created and publicly distributed brand messages undertaken by non-marketers. UGB can be contrasted with eBranding, which refers to use of the web to present a brand. They note potential of UGB as a marketing tool with benefits of cost effectiveness, the ability to track consumers, and immediate feedback regarding a brand and its products or services (Burmann, 2010). UGB can be effective in developing stronger relationships between brands and consumers, and eliciting greater engagement with consumers on social media (Geurina and Burch 2017).

The significance of social media should not be underestimated. Globally, the total number of social media users is forecasted to grow to 3.29 billion users in 2022, which will be $42.3 \%$ of the world's population (Appel et al. 2020). Moreover, there evidently exists a direct correlation between consumer participation on social media sites and their shopping intentions, which makes its use all the more important for businesses (Kapoor et al. 2018). 


\subsection{Digital Marketing}

Kannan and Li (2017) observe that the term "digital marketing" has evolved over time from the marketing of products and services using digital channels to a more umbrella concept, which they define as, "an adaptive, technology-enabled process by which firms collaborate with customers and partners to jointly create, communicate, deliver, and sustain value for all stakeholders".

We review the literature in areas of digital marketing that directly influence the customer buying process by increasing brand awareness, driving website traffic and generating sales leads:

- Social Media Marketing - Delivering messages and content through social media channels (Kotler et al. 2017, p158).

- Content Marketing - Creating and distributing content that is relevant to customers but also strongly associated with a certain brand (Kotler et al. 2017, p84).

- Marketing Automation - Automating tasks in the marketing and sales process to provide more relevant communications, typical delivered as personalised emails and website messages (Chaffey and Ellis-Chadwick 2016, p300).

\subsubsection{Social Media Marketing}

Messages posted by firms on their official social media pages are referred to as firmgenerated content (FGC) and can be mutually beneficial - informing customers of products while helping firms develop one-on-one customer relationships (Kumar et al. 2016). Marketers can share social media content and create brand post popularity by encouraging "likes" and comments. Value from fans comes from their level of engagement, popularising the brand content throughout their network of friends and associates (Kumar et al. 2016; Swani et al. 2017). Moreover, customers feel more engaged with products and organisations when they are able to submit feedback (Mangold and Faulds 2009).

Research into the effects of FGC and possible drivers for brand post popularity suggests that the vividness (degree of sense stimulation), interactivity (e.g. inclusion of a question), content (information, entertainment), posting in the top position and the valence of comments are related to the popularity (the number of likes and the number of comments) of a brand post (de Vries et al. 2012). Additionally, the use of warm and competent images, combined with appropriate narrative person (Chang et al. 2019) and the use of brand personality content can enhance consumer engagement with the message (Lee et al. 2018).

Research on Facebook and Twitter suggests that FGC posts are more likely to promote WOM if the content includes emotional sentiments, corporate brand names and embedded media 
such as video, image, text or a URL, e.g. a link to a company website. Moreover, posts should avoid explicitly commercial statements and "hard sell" strategies (Swani et al. 2013; Swani et al. 2014; Leek et al. 2016).

The nature of social media creates a reverberating "echoverse" for brand communication, forming complex feedback loops ("echoes") between the "universe" of corporate communications, news media and UGC. This can result in the amplification of positive and negative information, which can impact brands (Hewett et al. 2016). This has created challenges for companies, making it more complex to control brand images and relationship outcomes (Hennig-Thurau et al. 2010; Hennig-Thurau et al. 2013). Brand messages are no longer exclusively shaped by their owners. Rather, firms co-create their brand's experiences and meaning with their stakeholders, including customers and partners (Gensler et al. 2013; Swaminathan et al. 2020).

Research on the buying process has revealed that customers use social media mostly as an information source during the initial research stages, due to perceptions of its convenience, effectiveness and credibility. Significantly, reviews on social media induce or dissuade purchases. Thus, marketers should encourage customers to share experiences on social media and participate in conversations, listening and communicating promptly to address any complaints. The content and co-ordination of messages and interaction with the community are key for successful implementation (Valos et al. 2015). Moreover, businesses should harness that feedback positively to improve product offerings, customer relationships and profitability (Yogesh and Yesha 2014; Voramontri and Klieb 2018; Kannan and Li 2017; Kaplan and Haenlein 2010).

Social media is becoming an integral part of business strategy, enabling firms to communicate with their customers, influencing purchase decisions through fan popularisation of brand content and helping build brand loyalty (Alves et al. 2016; Mangold and Faulds 2009; Kaplan and Haenlein 2010; Swani et al. 2017).

\subsubsection{Content Marketing and Marketing Automation}

Pulizzi defines content marketing as, "creating and distributing valuable and compelling content to attract, acquire, and engage a clearly defined and understood target audience - with the objective of driving profitable customer action" (Pulizzi 2014, p5). Rather than pitching products or services, it involves delivering information to entertain customers and build an emotional connection. Content can be distributed through multiple channels, including social media, web and email (Pulizzi 2012). If a business can deliver consistent, valuable content, customers will reward that business with purchases and loyalty (Pulizzi 2014, p5-6). 
Researchers in B2B content marketing consider that it involves, "creating, distributing and sharing relevant, compelling and timely content to engage customers at the appropriate point in their buying consideration processes, such that it encourages them to convert to a business building" (Holliman and Rowley 2014; Järvinen and Taiminen 2016). Creating content that is useful, relevant and compelling to audiences requires a "publishing" approach, which involves developing an understanding of the audience and a cultural change from "selling" to "helping" (Holliman and Rowley 2014). Moreover, companies should distinguish their marketing communication objectives, such as general brand marketing from customer communications, to choose the most suitable content and channel (Karjaluoto et al. 2015).

Wang et al. (2019) researched content marketing in B2B professional services organisations and found that the number of sales leads and won opportunities were positively affected by digital content. They advocate the notion of content marketing as a service that provides added value for customers independently of the product being sold, value that will be reciprocated in sales results.

Marketing automation software provides capabilities to automate delivery of companygenerated content to prospects through a range of media, including e-mail, social networks and personalised landing pages. Moreover, it has potential to acquire and segment highquality leads (Świeczak 2013; Redding 2015).

Järvinen and Taiminen (2016) present a case study using marketing automation to email valuable and timely content to customers based on their recent online behaviours. The results of their research reinforce the idea that content must target customers' needs and solve their problems rather than promote company's products. They also integrated marketing automation with sales (CRM) to pass leads into one sales funnel, which was found to create business benefits.

Researchers investigating the role of marketing in the buying process have shown that email and display ads can be effective for converting sales, especially when used to contact customers at the time they are predicted to purchase (Li and Kannan 2014). Moreover, personalised emails regarding products based on customer interests can improve consumer satisfaction and build loyalty (Hasanata et al. 2019). However, overuse of emails may actually annoy customers, rendering them less effective (Li and Kannan 2014).

Research from Sahni et al. (2018) revealed that personalising customer emails benefits the advertisers, even when no informative content about the product or the company is included in the message. Simply adding the customer's name to the email's subject-line increased the probability of the recipient opening it, increased number of sales leads and reduced the number of individuals unsubscribing from the campaign. Moreover, personalisation could be 
valuable in garnering a consumer's interest and increasing the likelihood of him/her processing and responding to the rest of the advertising message.

\subsubsection{Summary}

The emphasis of digital marketing techniques is on creating content that is of value to attract customers and stimulate WOM. There are overlaps between those techniques: content can be distributed to customers over email through content marketing and/or social media through social media marketing. Moreover, marketing automation can be used to schedule both of those activities as part of campaign management.

Social media marketing also overlaps with the area of social CRM, but with an emphasis on marketing communications rather than resolving customer issues, although the boundaries between the two are blurring (Kotler et al. 2017, p158). This is reflected in the digital marketing literature, which recognises the importance of listening to customers, without detailing the approach or techniques for such activity. Similarly, there is little consideration for addressing issues a customer may raise. We now consider the social CRM literature for those topics.

\subsection{Social CRM}

Although several definitions of social CRM have been proposed in the literature, perhaps the most commonly accepted is Greenberg's, "a philosophy and a business strategy, supported by a technology platform, business rules, processes and social characteristics, designed to engage the customer in a collaborative conversation in order to provide mutually beneficial value in a trusted and transparent business environment". Moreover, "it's aimed at customer engagement rather than customer management" (Greenberg 2010, p34-35).

The term social CRM denotes a customer-oriented concept that integrates social media with CRM applications and thereby opens a broad spectrum of potential use cases in marketing, sales and service (Wittwer et al. 2017). With regard to the customer buying process, the main social CRM topics are social listening / publishing and customer service.

\subsubsection{Social Listening / Publishing}

Social listening can be defined as an active process of attending to, observing, interpreting and responding to a variety of stimuli through mediated, electronic and social channels (Stewart and Arnold 2016).

Stewart et al. (2017) describe a case study for an American university library using a manual process for social listening to improve communication and connections with customers. Their initial approach involved publishing and sharing content on social media. Later they shifted 
focus toward social listening to understand and address customer concerns. As a result, their user engagement increased on both Facebook and Twitter, and more meaningful interactions took place between staff and customers. They observe that social listening appears to have clear benefits among organisations and interpersonal relationships.

A "social media listening" application filters the web content based on various characteristics, based on keywords or comments about a particular topic, using data analysis tools to provide real-time information, which a company can use to make decisions (Orenga-Roglá and Chalmeta 2016). Reinhold and Alt refer to such an application as "social media monitoring" and identify constituent systems: monitoring (connecting to social media sites, extracting and interpreting content), management (passing that information to traditional CRM for processing), interaction (publishing responses back to social media) (Reinhold and Alt 2011; Reinhold and Alt 2012).

Choudhury and Harrigan (2014) present a model for social CRM, including a new construct of customer engagement to take cognisance of the impact of social media technologies and recommend data gathered from customer-social media interactions is fed into traditional CRM and utilised to drive future marketing decisions.

Wittwer et al. (2017) describe a model for determining "customer context" based on extracting "state" and "attribute" values for customers and environments from social media. They suggest such data could form a basis for customer-centred social CRM processes, such as definition of customer personas.

Researchers agree on the importance of social CRM as a bi-directional channel to communicate and collaborate with customers, discover consumer opinions relating to the company and its products, and to integrate social media content with CRM processes and systems (Reinhold and Alt 2011; Reinhold and Alt 2012; Choudhury and Harrigan 2014; Kubina et al. 2015; Wittwer et al. 2017; Acker et al. 2011). Moreover, CRM must evolve by producing contact points on social media that engage the consumer and provide value to both the company and the consumer (Malthouse et al. 2013).

\subsubsection{Social CRM for Customer Service}

In the context of social CRM, Greenberg describes customer service as, "the customer care activities that surround the purchase of a product or services" (Greenberg 2010, p345). This definition extends beyond handling complaints and includes inquiries and questions, which customers expect to be answered by the company. Greenberg notes that traditional CRM service channels frequently frustrate customers as they fail to properly resolve issues. $\mathrm{He}$ advocates a new customer service model based around social media sites, emphasising the 
value of customer-to-customer interactions, employees working closely with each other and proactively with customers, and use of a knowledge base (Greenberg 2010, p346-355).

Stefan Willi and Gamal (2012) describe a customer service approach where an employee is responsible for direct personal contact with the customer on two levels: an initial "introduction" level and a deeper "relationship level", where more information is exchanged after connecting on the social media platform. This interaction benefits both parties as the company gains details about the customer and the customer gains assistance from the company.

Lopez (2013) presents a case study for an organisation providing service on social media sites, Facebook and YouTube. Results from the study reveal the importance of a number of factors: tailoring bespoke content for each social media channel, responsive and real-time customer communication, the need for a shared knowledge base and an interdisciplinary team to provide effective customer service across social media platforms.

Ajmera et al. (2013) describe the construction of IBM SCION, a Social CRM analytics engine that mines conversational data from social media sites to enable enterprises to identify and respond to issues raised by customers. The SCION system's modules provide capability to extract data from site posts, analyse that data to identify the intent, prioritise posts based on topic and importance, and route posts to the business function considered the most appropriate to respond.

Bone et al. (2015) researched the effects of problem-solving customer participation in a peerto-peer problem-solving community among global B2B customers. Results revealed that customer participation in the community, in terms of helping oneself (posting questions) and helping others (responding to peer questions), reduced the participant's use of traditional customer support service channels.

Rossman et al. (2017) examined the efficacy of social media systems in customer complaint handling, as a useful complement and viable alternative to the traditional "hotline" channel. Their results demonstrated benefits from using the two channels in tandem. They also suggest that a satisfied customer in a social media channel is a superior asset for a firm than a customer served through traditional channels, because the former is more inclined to generate WOM communication.

Appel et al. (2020) note that, currently, many brands use social media platforms to provide customer care, addressing customers' specific questions and fixing problems. They predict that, in the future, social media-based customer care will become even more personalised and accessible and, perhaps, even pre-emptive using predictive approaches. 


\subsubsection{Summary}

The social CRM literature complements digital marketing by suggesting approaches to listen to and support customers on social media. However, many researchers appear to envisage social listening/publishing and social CRM as manual processes. We observe that, with the explosion of social media sites and the number of users, a manual solution would not be scalable and hence automated support is required.

The literature also revealed requirements to provide proactive customer service, for collaboration between employees and customers, and making a knowledge database accessible to employees and customers. Significantly, Ajmera et al. (2013) was the only example we found describing integration of automated social listening / publishing with CRM customer service capability.

The Social CRM literature does not fully discuss the complexities that may arise in customers moving between channels or the wider context of the customer purchase process. However, such topics fall under the domain of omnichannel CRM, which we now consider.

\subsection{Omnichannel CRM and Customer Buying Process}

\subsubsection{Omnichannel CRM}

In 2011, Rigby noted that the number of digital channels (e.g. websites, email, social media, online communities, online shops and mobile devices) available to customers was dramatically increasing and observed, "Unless conventional merchants adopt an entirely new perspective - one that allows them to integrate disparate channels into a single seamless omnichannel experience - they are likely to be swept away" (Rigby 2011).

Omnichannel CRM places emphasis on the interplay between channels and providing a seamless customer experience. Customers select and use channels interchangeably during the search and purchase process with "showrooming" (search in store, buy online) and "webrooming" (search online, buy in store). Moreover, it is difficult for firms to control that usage (Verhoef et al. 2015).

Successful implementation requires omnichannel management, which can be defined as, "the synergetic management of the numerous available channels and customer touchpoints, in such a way that the customer experience across channels and the performance over channels is optimized." In turn, that requires different channels to be integrated in a manner that enhances performance not only of the channel but also of the brand (Verhoef et al. 2015). Cao and Li (2015) define cross-channel integration as, "the degree to which a firm coordinates the objectives, design, and deployment of its channels to create synergies for the firm and offer 
particular benefits to its consumers." They identify mechanisms by which cross-channel integration can affect firm's sales growth and define full integration as, "retailers optimize established channels collaboratively, focusing on activities linked to consumers' seamless shopping experience." The required capabilities for this are (Cao and Li 2015):

- Alignment of fundamentals - Alignment of services / products / promotions / loyalty programmes across channels.

- Centralisation of back-end system - Integration of systems and customer database across channels and centralised call centre services across channels.

- Organisation transformation - Sharing knowledge across channels, recruiting competencies in digital and retail commerce, and changing organisational structure to adapt to integrated channels.

Brynjolfsson et al. (2013) recognise that the omnichannel environment is becoming increasingly competitive. They therefore suggest strategies such as encouraging customer interaction (providing content and reviews), information sharing through cross-channel integration, and using data analytics and customer knowledge to provide differentiation. The key message is, "in an omnichannel world there is a premium on learning rapidly from consumers and catering to their needs".

Lemon and Verhoef (2016) note that the introduction of mobile devices may induce even more switching across channels, adding complexity to the customer journey. Other researchers agree the scope of channels should include search, display, email, affiliate schemes, referral websites and a mobile app (Verhoef et al. 2015; Xu et al. 2014).

Research on the use of mobile technologies has mainly considered the effects of mobile promotions and the adoption of mobile shopping on purchase behaviour (Lemon and Verhoef 2016). Mobile offers new marketing tactics for firms. For example, it enables retailers to provide tailored, time-sensitive, and location sensitive advertising and promotions in store, as well as personalised marketing offers (Bart et al. 2014; Hui et al. 2013).

Wang et al. (2016) observe a firm can use mobile app technology to enable consumers to engage with its brand even when they are on the move. Such engagement has potential to enhance consumer experience, brand loyalty and, ultimately, revenue growth. However, consumers only adopt a mobile app and keep using it when they believe it provides value, which might well require costly maintenance and frequent updating. Those messages are reinforced by research on the influence of a brand's mobile app's interactive features (information lookups and check-ins) on spending levels. Results revealed that adoption and continued use of the branded app increased future spending but, after discontinued use, customer spending decreased (Su Jung et al. 2015; Wang et al. 2015). 


\subsubsection{Customer Buying Process}

Lemon and Verhoef (2016) conceptualise the customer buying process in three stages: prepurchase (including search), purchase and post-purchase (including after care and repurchase). This process is iterative and has potential to affect customer experience. They conceptualise customer experience as a customer's journey over time during iterations of the buying process across multiple touchpoints (customer channel interactions). They identify four categories of touchpoint, only some of which are under the firm's control: brand-owned, partner-owned, customer-owned and social / external. The customer might interact with each category in each stage of the process.

Other researchers identify five stages for the buying decision process: problem recognition, information search, alternative evaluation, purchase decision and post-purchase. The initial three stages are a refinement of "pre-purchase" and the ones in which social media is mostly used during the buying process (Voramontri and Klieb, 2018; Yogesh and Yesha, 2014).

From a practitioner's perspective, Edelman and colleagues suggest that the omnichannel buying process comprises of four stages: (1) consider, (2) evaluate, (3) buy and (4) enjoy, advocate, bond. The first two stages are a refinement of "pre-purchase and the last stage represents sub-stages of "post-purchase". Moreover, they suggest that a "loyalty loop" may be formed where, in subsequent iterations of the purchase process, the customer by-passes prepurchase and moves straight to "buy". They suggest four approaches to practical implementation of that loyalty loop: automation (digitising journey's steps), proactive personalisation (using customer information to tailor content), contextual interaction (using knowledge about where a customer is in a journey to influence the next interaction) and journey's innovation (ongoing experimentation and active analysis of customer needs, technologies and services) (Edelman 2010; Edelman et al. 2015).

Cetină et al. (2012) researched factors that affect a customer's decision-buying process and identified three classes of stimuli: marketing, web experience and external (e.g. personal and environmental) factors. They conclude companies should continuously develop their online marketing activity by exploiting the interaction, bidirectional communication and WOM facilitated by web and social media sites.

Bucko et al. (2018) researched factors that affect consumer decision to purchase from the online store in the Slovak market. They identified the following key factors: price, availability, social proof (reviews about the product and seller), scarcity (limited product quantity and limited time of offer), product details, conditions and social media presence (number of followers and social media activity). They noted that knowledge of those factors can be used to optimise online shops and it is crucial those shops provide a good experience 
for website visitors. A positive experience might result in higher revenues, while a negative one might result in the permanent loss of customers.

\subsubsection{Summary}

The literature considers company management and customer use of channels, within the context of the stages of the buying process. This complements digital marketing, where the focus is on promoting brands and products, and social CRM, where the focus is on addressing customer issues.

The literature indicates that in an omnichannel environment, the customer should be free to choose channels arbitrarily throughout the purchase process. Such a deployment will require omnichannel management, which in turn will require cross-channel integration. However, we note that the definition of full integration ( $\mathrm{CaO}$ and $\mathrm{Li} 2015$ ) extends beyond the purchase process and channels as it encompasses the wider landscape of the organisation, employees and systems.

In the following section, we adopt a customer-centric perspective to explore the potential impact of social media, channels and purchase process on the customer.

\subsection{A Customer-centric Perspective}

In this section, we adopt the customer's viewpoint and examine the relationship between social media and the purchase process, which comprises the concepts of customer experience, experience management, engagement and engagement behaviours.

\subsubsection{Customer Experience (CX)}

Meyer and Schwager (2007) define CX as, "the internal and subjective response customers have to any direct or indirect contact with a company." Verhoef et al. (2009) build on that research identifying several determinants of CX: social environment (facilitated and stimulated by on-line environments and brand communities), service interface, retail atmosphere, assortment, price and promotions. In subsequent research, Lemon and Verhoef (2016, p.71) define CX as, "a multidimensional construct focusing on a customer's cognitive, emotional, behavioural, sensorial, and social responses to a firm's offerings during the customer's entire purchase journey."

De Keyser et al. (2015) observe that people continuously strive to satisfy specific needs and wants thereby engaging in goal driven processes aimed at reaching a desired end state.

Moreover, such human goal pursuit is critical for customer experience. They distinguish between "event-specific" experience, which is linked to a customer-firm interaction and 
"dynamic", which is the overall experience that evolves over time and is reflective of multiple customer-firm interactions.

Many researchers agree that experience resides in the entire context of pre-purchase, purchase, and post-purchase as a function of interactions with all of the touchpoints that together form the customer journey (Patrício et al 2011; Rawson et al. 2013; Lemon and Verhoef 2016; Calder et al. 2018).

Customer experience is an important strategic objective for service firms as it is a key determinant of consumer behaviour and has significant positive influence on customer satisfaction, word-of-mouth and loyalty (Klaus and Maklan, 2011; Brakus et al. 2009). Recognition of this has led to the concept of Customer Experience Management (CEM), which can be defined as, "a retailer's strategy to engineer the customer's experience in such a way as to create value both to the customer and the firm" (Verhoef et al. 2009). We note the apparent overlap and synergy between this definition of customer experience management and the earlier definition of omnichannel management (Verhoef et al. 2015). Both definitions emphasise customer experience and value for both customer and firm.

Fatma (2014) identifies the antecedents of CEM as: brand experience, channel interactions, service interface, physical environment, social environment, price and promotions. The major consequences are identified as: customer satisfaction, customer loyalty and customer equity.

Patrício et al. (2011) advocate an approach to CEM that is based on process and method of service design to improve the experience for all customer interactions through service interfaces across the customer journey. Homburg et al. (2017) suggest that CEM is also an issue of corporate culture. They identify strategic directions for touchpoint design and orientation as part of the wider customer journeys across the stages of the buying process with the view of optimising CX. Ultimately, the purpose is to enhance customer loyalty and encourage the customers' intentions to live again through a touchpoint journey of a firm by transitioning from post-purchase to pre-purchase (Homburg et a. 2017).

Wereda and Grzybowska (2016) note that the creation of an excellent customer experience requires a continuous dialogue with customers and innovating in response to it. They reference a study that found that customers who had a positive experience were more likely to repurchase and recommend the business to a friend and less likely to switch to a competitor.

Researchers have contrasted CEM with traditional CRM. CEM focuses on experiences that customers have at touchpoints in course of their interaction with the firm. Business leaders use that information to manage products and services strategically, create better customer experiences and build relationships. In contrast, the focus of CRM is on capturing, recording 
and distributing customer details and the history of transactions (Meyer and Schwager 2007; Fatma 2014).

\subsubsection{Customer Engagement (CE)}

Traditionally, marketers used the term customer satisfaction as a guiding objective but, increasingly, they are focusing on engagement as a complement or alternative. Whereas satisfaction is an integrative, usually post hoc, evaluation of a product or service, engagement is a highly personal and motivational state arising out of customer experiences with a product or service (Calder et al 2013).

The importance of Customer Engagement (CE) has been widely recognised throughout the academic literature. Brodie et al. (2011) provide what is perhaps the most widely accepted general definition, "Customer engagement (CE) is a psychological state that occurs by virtue of interactive, cocreative customer experiences with a focal agent/object (e.g., a brand) in focal service relationships." Moreover, it is a multidimensional concept involving cognitive, emotional and/or behavioural dimensions (Brodie at al. 2011). That definition builds on the work of earlier researchers who had conceptualised engagement as a psychological state (Patterson et al. 2006), psychological process (Bowden 2009), or as being motivational in nature (Mollen and Wilson 2010; Vivek et al. 2012; Hollebeek 2011).

Academics consider CE to be a nomological concept associated with antecedents (e.g. participation, involvement, rapport) and consequences (e.g. commitment, word of mouth, brand community involvement, loyalty) (Bowden 2009; Patterson et al. 2006; Brodie et al. 2011, Vivek et al. 2012; Pansari and Kumar 2017). Another consequence of CE is customer engagement behaviour (CEB), which can be defined as, "a customer's behavioural manifestation that have a brand or firm focus, beyond purchase, resulting from motivational drivers" (van Doorn et al. 2010, p. 254).

Kumar and Pansari identify that the value of CE to a firm includes both direct and indirect contributions. This comprises customer behaviours in the areas of purchasing, referrals, influencing, knowledge and conversations about the brand on social media. (Kumar et al. 2010; Kumar and Pansari 2015; Pansari and Kumar 2017). De Keyser et al. (2015) agree and suggest such value is driven by past, present and future CXs and the extent to which the customer considers them positive or negative. Positive experiences will lead to increased engagement, while negative experiences will lead to lower engagement. Hence, CX flows into both customer value and CE.

The Brodie et al. (2011) definition of customer engagement arises out of the different ways in which a product or service can be experienced by a customer. Customer experiences exist on a continuum ranging from detached to intense. High engagement comes from rich, qualitative, 
"felt" experiences, especially when that leads to a larger personal goal (Calder et al. 2013; Calder et al. 2016).

Lemon and Verhoef (2016) note that customer engagement focuses on the extent to which the customer "reaches out" and initiates contact with the firm. Such "reaching out" constitutes touchpoints along the customer journey during the purchase process and results in cognitive, emotional, behavioural, sensorial and social responses by the customer. Hence, customer engagement becomes a part of the overall customer experience along his/her journey and continually judging this journey against response thresholds of co-occurring experiences (Homburg et al. 2017; Calder et al. 2009).

In the section "Social Media, Customers and Brands"”, we discussed customer interaction with brands on social media. Academics consider such interactions to be forms of CEB (Brodie at al. 2013; Cheung et al. 2011). Vivek et al (2012) emphasise the importance of customer participation in online communities as even low-involvement foci can be highly engaging to individuals. There is a great opportunity for organisations to engage customers by encouraging customer creation or sharing of UGC.

Researchers emphasise the positive outcomes arising from CE on social media, which may include customer loyalty to and satisfaction with the brand and community (Jayasingh, 2019); empowerment, trust and commitment towards other members in the community (Brodie et al. 2013; Hollebeek et al. 2014); WOM intention and re-purchase intention (Chan et al. 2014) and the development of sharing intentions (Carlson et al. 2019). Moreover, CE is a source of value for the firm and the participants (Schau et al. 2009; Alexander and Jaakkola, 2015; Jaakkola and Alexander, 2014).

Engagement can be increased in cases where consumers vigorously participate, advocate or interact with the brand, e.g. through social media (Malthouse et al. 2016a; Maslowska et al. 2016). However, engagement is not produced by simply being "on" a certain kind of media, digital, social, mobile or otherwise. Marketers must design specific experiences using these media effectively to connect customers with brands (Malthouse et al. 2016b; Calder et al. 2018). Carlson et al. (2018) identify approaches for tailoring social media brand pages to proactively stimulate CEB intentions relating to customer feedback and collaboration. These involve maximising the quality of the page content, page interactivity, page sociability and customer contact quality.

Hollebeek et al. (2019) observe that customer engagement and CRM are mutually beneficial. Customers' interaction through social media constitutes learning, knowledge sharing and cocreation, which can inform CRM. Similarly, CRM can be used to engage customers, with engaged customers typically providing longer-lasting, stronger and more stable relationships, 
greater customer contributions and responsiveness, increased referrals and customer advocacy (Malthouse et al. 2013; Kumar and Pansari 2015).

\subsubsection{Summary}

The literature indicates that touchpoints on the customer journey during the purchase process affect CX, which in turn flows into CE. This is reinforced by customer interaction with brands on social media as a form of CEB.

Researchers have observed that, although considerable attention has been devoted to understanding the customer experience, given the importance of creating effective omnichannel experiences, there still remains a need to investigate how to manage the experience across the entire customer journey, including touchpoints and channels (Ostrom et al. 2015; Lemon \& Verhoef 2016).

Dwivedi et al. (2020) state that offering omnichannel consumption experiences, whereby interactions with a variety of channels complement rather than compete with each other, enhances the overall customer experience. Consumers expect a seamless, integrated and holistic customer experience, regardless of the channel., However, despite channel integration efforts by companies, according to recent market research reports, many customers are disappointed with their experiences. As such, the design of CX initiatives involving digital and social media channels and their integration will become paramount in order to unlock the full extent of CEBs and maximise mutual value fulfilment for the customer and the firm. This represents a challenge for research. Lemon and Verhoef (2016) agree with that perspective and raise the question: How can firms effectively use technology in CX management?

\section{The CRM Virtuous Circle}

Reviewing the aforementioned literature, key themes emerge. Social media influences customers through brand/product information and WOM by other users. An increasing number of digital channels are available for customers to use and should provide a seamless omnichannel experience during the buying process. To positively influence a customer's purchase decision, a company should embrace digital channels, including social media, and provide helpful, personalised content. Moreover, applying customer experience management to enhance customer experience during the buying process may improve customer engagement and, ultimately, brand performance.

We observe the overlaps between the different areas of literature with the topics of social media interaction, buying process and customer focus recurring throughout. However, it 
appears researchers tend to consider those topics from perspectives of specific realms rather than examine them holistically.

In light of those observations, we construct a new omnichannel purchasing model, referencing theoretical concepts contributed from the literature, consider an illustrative worked example and discuss two approaches to its implementation. This model aims to provide a holistic view across the literature areas, identifying and embracing synergies.

\subsection{Theoretical Model}

We propose a theoretical model consisting of the following elements:

1. Buying process - This is conceptualised in three stages: pre-purchase (research), purchase, and post-purchase (after-sales support and re-purchase) (Lemon and Verhoef 2016).

2. Channels - The buying process is facilitated by a set of channels (the medium through which the firm and the customer interact - Verhoef et al. 2015), some owned by the firm, e.g. website and online shop and others owned externally, e.g. social media sites. This can also include non-digital channels, e.g. contact centre or physical store. The channels are not explicitly specified to provide flexibility in the ones that a given organisation may choose to deploy.

3. Content - Each channel may contain any form(s) of content published by customers (e.g. UGC, UGB) and/or the firm (e.g. FGC) (Kaplan and Haenlein, 2010; Burmann 2010; Kumar et al. 2016).

4. Touchpoints - Each customer interaction with content on a channel forms a touchpoint, e.g., opening an email, clicking on a link in an email, searching a website, publishing a product, a service review on social media, telephoning a contact centre or visiting a store (Lemon and Verhoef, 2016).

5. Customer journey - The sequence of touchpoints encountered by a customer during execution of the buying process forms that customer's journey (Lemon and Verhoef 2016; Homburg et al. 2017).

6. Journey repository - Stores data gathered from touchpoint interactions and transactions on the customer journey during the buying process. (The concept of using a journey repository in this context does not appear in any of the literature reviewed.)

The model facilitates an omnichannel customer experience as the customer is able to use any channel at any stage during the buying process. As non-digital channels are not excluded, the model conceptually supports customer behaviour such as "webrooming" or "showrooming" 
(Verhoef et al. 2015). However, this raise challenges for implementation, which we discuss in the section "Implementation of the Model".

The journey repository is central to the operation of the model and offers powerful potential:

- As customer(s) access content at touchpoints, a firm is able to respond by publishing content, allowing the company and customer(s) to interact. The firm can use data in the journey repository to personalise responses and support each customer on his/her journey during the buying process.

- As the repository contains customer interaction and transaction data gathered during the customer journey, it can help facilitate construction of a single view of the customer.

- The information it contains can be used to facilitate approaches to cross-channel integration (Cao and Li 2015), omnichannel management (Verhoef et al. 2015) and customer experience management (Verhoef et al. 2009).

Each iteration of the purchase process provides potential to impact customer experience (Lemon and Verhoef 2016) and customer engagement (Brodie at al. 2011; 2013). This, combined with an approach to customer experience management, provides potential to enhance that customer experience and engagement.

We discuss the above concepts from a practice perspective in the following subsections.

\subsection{A Worked Example of the Model}

We consider a customer who is an avid skier buying a new ski jacket from a ski-apparel company. Figure 1 illustrates the customer going through the buying process. Swimlanes represent the channels: social media (denoting multiple sites), email, website and online shop. The customer's journey is the sequence of customer touchpoints across those channels, represented as numbered boxes in each swimlane. 


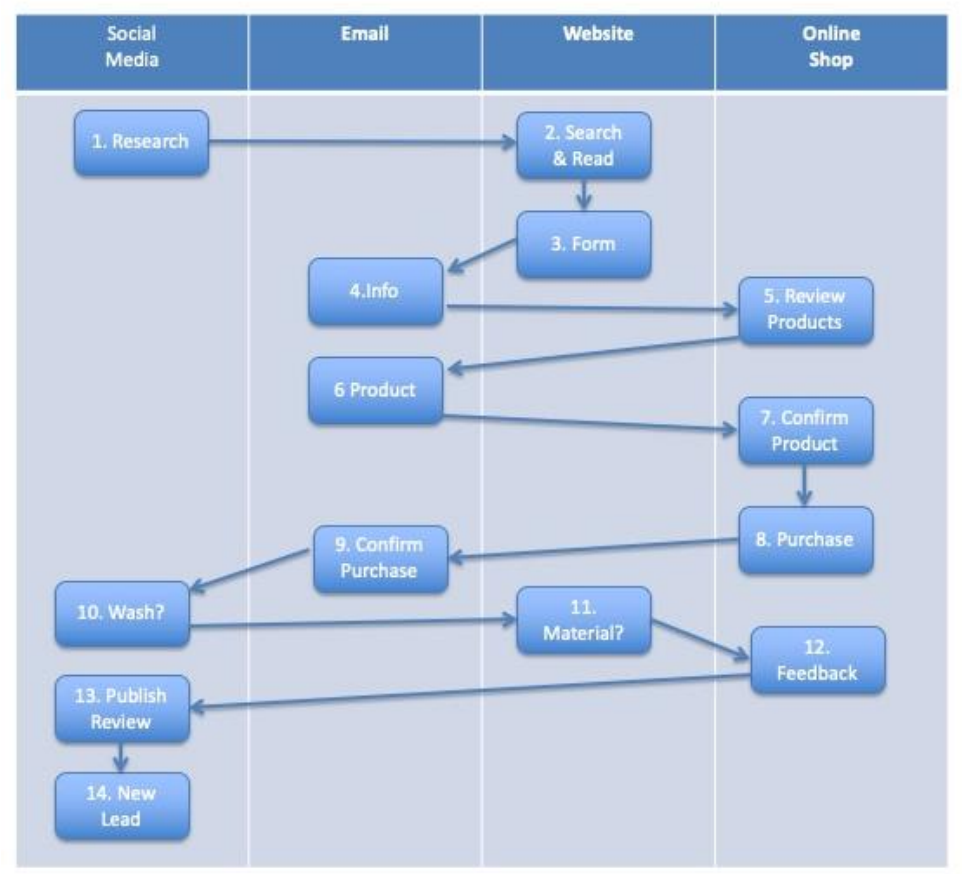

Figure 1. Worked Example of the Model

1. Research - The customer visits social media sites and discovers UGC brand/product reviews, customer experience blogs - some of which relates to the skiapparel company's brand and products. The customer also browses FGC provided by the company in response to customer comments, including videos, images and URL links to the company's website and online shop. (Pre-purchase stage)

2. Search and Read - Intrigued to learn more, the customer navigates the link to the company's website, which displays a prompt offering assistance. The customer provides some keywords and is presented with links to helpful articles and videos containing information about the brand and products. (Pre-purchase stage)

3. Form - The customer completes a form on the website to receive promotional offers and indicates the types of product that are of interest. (Pre-purchase stage)

4. Info Email - The customer receives a personalised email containing information for the products and URL links to the company's website, online shop and social media pages. (Pre-purchase stage)

5. Review Products - Intrigued by that email, the customer navigates the link to the online shop, reads customer feedback on the brand and products. (Pre-purchase stage)

6. Product Email - The customer receives a personalised email from the company containing an offer for the products searched. The email includes URL links to the website and online shop. (Pre-purchase stage)

7. Confirm Product - Having completed the research, the customer opens the email and navigates a link to the product in the online shop to complete final evaluation before purchase. (Pre-purchase stage) 
8. Purchase - The customer attempts to purchase but encounters a problem regarding payment options. A semi-automated process asks whether the customer would like assistance and a CSA (Customer Service Agent) provides support allowing the purchase to complete. (Purchase stage)

9. Confirm Purchase Email - The customer receives an email confirming the purchase and inviting him/her to submit a review and/or feedback. That email contains links to the company's social media pages and links to complementary products in the online shop. (Purchase stage)

10. Wash? - The customer receives the jacket but has a question relating to washing the garment, which he/she raises as a post on social media sites. The firm "hears" that question and responds posting a video describing how to wash the jacket without damaging the waterproofing. (Post-purchase stage)

11. Material? - The customer has another question relating to the jacket's material and visits the company's website. The customer is helped by a virtual customer assistant and, after providing keywords, is presented with a knowledge article that contains a full description of the material. (Post-purchase stage)

12. Feedback - The customer visits the online shop to submit feedback and, while there, reads a comment from another consumer who has similar questions. The customer shares a link to the video on the social media site and uploads the knowledge article. (Post-purchase stage)

13. Publish Review - The customer returns to the social media sites and uploads content based on the experience (brand and product reviews) and considers purchase of further items. (Post-purchase stage)

14. New Lead - New visitors to those social media sites read the content posted by that customer and potentially enter the buying process as sales leads. (Pre-purchase stage)

Our example illustrates use of techniques discussed in the literature survey:

- Digital marketing - Use of social media marketing (step 1), personalised communication (steps 2 and 6), campaign management (step 6) and content marketing (steps 4, 5 and 6). The aim is to provide content that is relevant, helpful and stimulating, while promoting the brand and products, to influence the customer's journey and enhance the overall experience.

- Social CRM - Use of social listening and publishing (step 1); proactive customer service during pre-purchase (step 2), purchase (step 8) and post-purchase with social CRM customer service (step 10); and a knowledge database (step 2 providing a document and step 10 providing a video).

- Omnichannel CRM - The management and co-ordination of channels that a customer is free to choose from, arbitrarily, throughout the buying process. 
During each customer's journey, the touchpoint interactions are stored in the journey's repository. The firm then analyses journey's repository data to answer questions such as: Which touchpoints were used on customer journeys? Which customer journeys were completed/abandoned? Which content stimulated customer responses? The firm uses the insights gained to refine and re-engineer channels and optimise content to improve the customer journey (termed “journey innovation” by Edelman et al. 2015), implementing omnichannel management and customer experience management.

The techniques illustrated in the worked example facilitate interaction and, crucially, provide a framework for collaboration between a firm and its customers. We refer to this as the "virtuous circle" of omnichannel CRM. It is conceptualised as a circle as it centres around customer use of channels, especially social media. A typical customer journey will commence on social media during research and complete with a return to the social media to post reviews and feedback. It is virtuous as it benefits both the customer and the business. The customer benefits from an enhanced experience. As that experience drives engagement and improves sales, the company benefits directly. Notably, if the customer provides positive feedback on social media, which then encourages new customers to purchase, the company also benefits indirectly.

\subsection{Implementation of the Model}

We consider two approaches to implementing the model and its constituent elements: buying process, channels, content, touchpoints, customer journey and journey repository. The component capabilities we identify are all offered in the market place by CRM and/or digital marketing vendors.

\subsubsection{Centralised Approach to Implementation}

Figure 2 illustrates a "centralised" approach to implementation. The customer and channels are depicted at the top of the diagram with the components that support the channels shown underneath as modules within a CRM platform. 


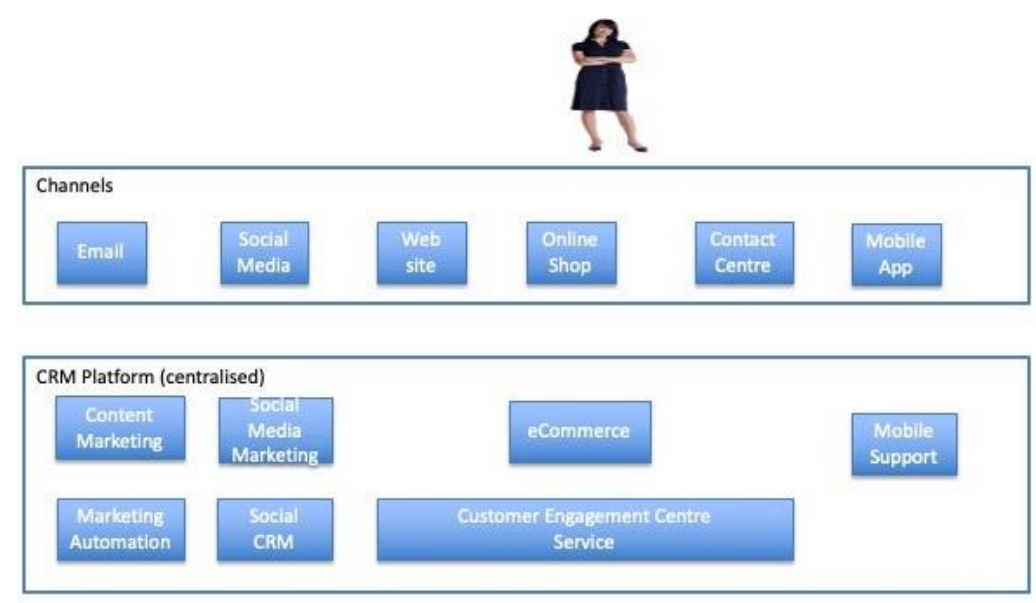

Figure 2. Centralised Implementation Approach

The firm can use the content marketing component to publish content to channels (Pulizzi 2012; 2014) that is helpful and includes media and URL links to websites and, where appropriate, is personalised to individual customers (termed "proactive personalisation" by Edelman et al. 2015).

To support the customer journey across the buying process, the marketing automation application includes a "journey management" component (termed "contextual interaction" by Edelman et al. 2015) that enables design and automation of customer journeys. It uses eventdriven triggers to proactively respond to customer interactions at touchpoints and deliver the right message, at the right time. It can also copy those interactions to the journey repository for future reference and analysis.

The social media management component (termed "social media listening" by Orenga-Roglá and Chalmeta 2016 and "social media monitoring" by Reinhold and Alt 2011; 2012) provides automated capability to gather content from social media, analyse customer sentiments and publish content to social media. It supports both social media marketing and social CRM customer service, aiding CSAs in responding to users' comments and questions. Notably, once information has been published on social media for one customer, it can be available for all potential customers.

The CRM Customer Engagement Centre (CEC) can be defined as, "software applications used to provide customer service and support by engaging intelligently - both proactively and reactively - with customers by answering questions, solving problems and giving advice" (Manusama et al. 2020). It facilitates omnichannel customer service across channels and includes applications such as social media management (discussed above), live chat, virtual customer assistant (VCA) and a searchable knowledge base. Such applications provide capability to respond to a customer on a one-to-one basis in real-time, as illustrated in the worked example. 
The online shop is implemented on an e-commerce module and is accessible from the firm's website. The mobile app is integrated through a mobile support module and provides functionality for a user to access the online shop through a mobile device.

This implementation is termed "centralised" as the above components are integrated with a core CRM system that provides traditional CRM capabilities (sales, service, analytics). This allows customer details, interaction and transaction data from those components to be combined in one central CRM database (journey repository).

We noted that Cao and $\mathrm{Li}$ (2015)'s criteria for achieving full cross-channel integration encompass the organisation, processes and systems. However, within the context of our model, the CRM database offers capabilities to facilitate such integration. It is a centralised customer database, supports customer service operations and shares data and knowledge across channels as all of the components are able to access it.

The CRM analytics tools can be used to analyse the CRM database to gain insights into customer touchpoints, channels and content. The insights gained can be used as a feedback mechanism to update the components, creating value for both the customer and the firm. Thus, it acts as an enabler to facilitate omnichannel management and customer experience management.

The theoretical model conceptually includes both digital and non-digital channels, and supports customer behaviour such as "webrooming" (search online, buy in store) and "showrooming" (search in store, buy online). We observe there is an implementation challenge for tracking customer touchpoint interactions in non-digital channels, e.g. a customer viewing products and information in a store. However, customer store purchase transactions made through an integrated ePOS or eCommerce module could be captured in the CRM platform and database. By relating that customer transaction data to customer data captured through other digital channels, there would be potential to gain insights into "webrooming" behaviour.

\subsubsection{De-centralised Approach to Implementation}

Figure 3 illustrates a "de-centralised" approach to implementation. This involves the same components as the "centralised" approach but they have been implemented as disparate systems that are not pre-integrated with a core CRM system. This could occur if those systems were deployed over time and provided by separate vendors. 

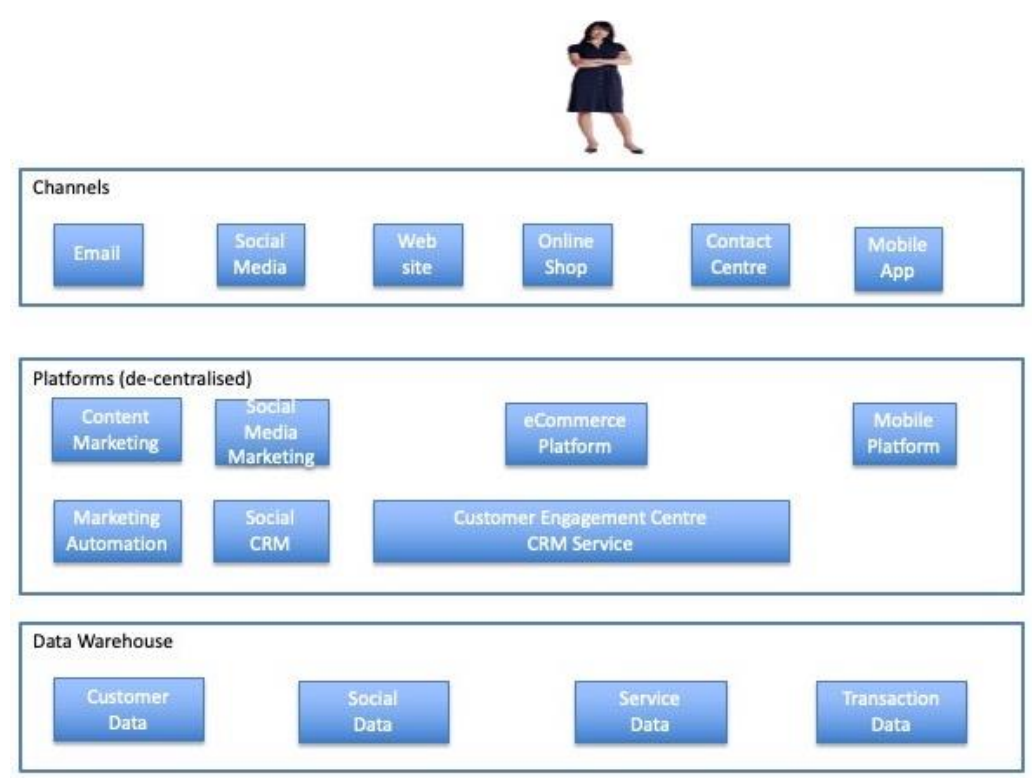

Figure 3. De-centralised Implementation Approach

Such a solution can create challenges for coordinating the channels and components, sharing data across those channels and components, and constructing a view of the customer. A common industry solution to those challenges is to deploy a data warehouse (journey repository) into which customer and transaction data from the components is stored. Business Intelligence (BI) tools can be used to analyse the data in that data warehouse to gain insights into customer behaviour, and facilitate omnichannel management and customer experience management, as discussed for the centralised approach.

To implement information sharing across channels and facilitate cross-channel integration, components are able to retrieve data from the data warehouse and data can be fed proactively to those components using data warehouse feedback interfaces (Cattrall, 2016). Similarly, in such an omnichannel environment, the data warehouse can be used to construct a single customer view from data gathered from components (Cattrall, 2017).

\subsection{Summary}

Regardless of which implementation approach is taken - centralised or de-centralised - the model provides a framework in which marketing, sales and service (including social CRM) can interact with customers.

The journey repository is central to the operation and implementation of the model: it supports firm-customer interaction and captures customer data that can provide insights to facilitate omnichannel management and customer experience management. Thus, it provides an answer to Lemon and Verhoef (2016)'s question of how technology could be used effectively in CX management. Moreover, in response to the research challenge noted by 
Dwivedi et al. (2020), it represents a potential to design and engineer a seamless, integrated customer experience to unlock the full extent of customer engagement and maximise mutual value fulfilment for the customer and the firm.

\section{Case Study of a Business Example}

We consider here an example of business implementation of our model using the "decentralised" approach and discuss the implementation challenges encountered across digital marketing, social CRM and omnichannel CRM (including customer service).

A multi-brand, home-shopping retailer had successfully ported its operations from a paperbased product catalogue to an on-line shop integrated with its website. It recognised the customer buying process involved pre-purchase (research and evaluation), purchase and postpurchase stages. The online shop channel was implemented on an e-commerce platform that facilitated customer reviews and feedback. The product catalogue and customer reviews represented key forms of content.

The retailer now wanted to increase revenue through deployment of additional digital channels: social media, email, mobile text and mobile app. It recognised that not all customers would own a computer but most would own a mobile phone and communication would be crucial for good customer experience management. It was essential to deliver the right message, at the right time, through the right channel to each customer.

For each brand, the retailer created social media community pages, adding informative content with links to the associated website and inviting visitors to post messages to the company. The firm periodically updated the pages with photographs of products and details of offers. Customers were able to post comments to which the firm responded.

New customers were able to register on the website and opt-in for promotional offers specifying channel preferences for receiving messages. To facilitate communication, software components were deployed to format and deliver messages through mobile app, mobile text and email, based on specified customer preferences. To facilitate cross-channel integration between those components, the company then deployed a journey management component, which was able to detect customer interactions across key touchpoints and determine the best response in the preferred channel.

The online shop was accessible to customers from a web browser or the mobile app. The resulting sales transactions were passed to back-office systems for fulfilment and to a data warehouse (journey repository) for analysis. 
To support digital marketing, a campaign management tool was deployed on top of the data warehouse to send personalised content marketing offers to customers, across their channel of choice, based on purchase and website (touchpoint) data.

Being a de-centralised implementation, there was no core CRM platform. The interfaces between components and the data warehouse had to be constructed and only some types of touchpoint data (purchases, email registrations and website interactions) were stored in that data warehouse. This presented a barrier to constructing a comprehensive single customer view. The lack of journey data also presented a barrier to analysis for omnichannel management and customer experience management.

Customer purchases were also passed to a customer account management component that was used for financial processing and to support customer service. However, that component was separate to the messaging, e-commerce and data warehouse components. Significantly, the team responsible for handling customer issues on social media used a manual process and was separate to the customer account management team. This resulted in social media responses inviting customers to contact customer services rather than proactive resolution of the underlying issues. In turn, this triggered negative customer comments and word-of-mouth on social media. This illustrates Greenberg's sentiments concerning common customer frustrations and the need for a community-based service that provides immediate problem resolution and for collaboration both with the customer and internally within the firm (Greenberg 2010, p.349-353). To address those issues, the company undertook an exercise to identify how digital channels could be enhanced with CEC capabilities, e.g. social media management, VCA, live chat and a knowledge base.

However, despite the above challenges, the company is now one of the major UK digital retailers with over $60 \%$ of online sales coming from mobile devices.

\section{Conclusions and Implications}

In our introduction, we noted key topics and questions raised by the Marketing Science Institute (MSI 2020). The topic, "Strategies to prioritize customer value at all touchpoints during the omnichannel customer journey" raised the questions: How does the increasingly complex technological, promotional and advertising ecosystem affect the customer journey? What are the most effective strategies to driver deeper, long-lasting customer engagement/loyalty with the firm? The topic, "Managing brand experience and promotion across the customer journey" raised the question: How does omnichannel retailing interact with the purchase funnel? We summarise here the insights and potential answers that we have provided. 
We presented a new model of the customer omnichannel purchasing process, which we characterise as a "virtuous circle" as it centres around customers' use of channels and social media and offers potential to benefit both customers and companies. This model combines elements discussed in academic literature - purchase process, channels, content, touchpoints, customer journey - into a single framework.

The model also contains a new element, the journey repository, which, to the best of our knowledge, has not been previously identified in the academic literature in this context. We discussed two approaches to implementation of the model, identifying component technologies currently available in the market. We described how the journey repository could be used as a feedback mechanism to facilitate approaches to cross-channel integration, omnichannel management and customer experience management. As the academic literature clearly links the buying process, customer experience and customer engagement/loyalty, this forms an approach to driving deeper relationships to create value for both the customer and the firm.

Our aim was to bridge academic and industry communities and we believe the model has positive implications for researchers and practitioners.

From a research perspective, our model provides a framework to support analysis of the customer buying process and its constituent elements and analysis of the relationship between the buying process and customer experience/engagement. In addition, it sheds new light on the relationship and synergies between digital marketing, social CRM and omnichannel CRM.

From an industry perspective, our model has potential to support marketing analysis and sales of products or services in B2B / B2C contexts to achieve marketing and sales targets. Two approaches to implementation were discussed, along with an illustrative case study of a business example. The components identified are currently available in the marketplace and offer genuine potential to improve retail performance.

Our model integrates aspects of digital marketing, social CRM, and omnichannel CRM into a framework that can be utilised to facilitate the customer journey on the purchase process. Successful implementation of the model is likely to necessitate co-ordination and collaboration across those organisational areas. However, this has potential to create organisational challenges and require cultural change for any firm in which those functions and employees are deployed as disparate teams or departments. We echo here Greenberg's sentiments concerning the need for collaboration, not only with the customer, but also internally within the firm (Greenberg 2010, p.353). 
We invite researchers to further explore implications of our model. There would be benefit in future empirical research to gather qualitative/quantitative data on its application.

The model provides a framework for research into the purchase process and its constituent elements. There are questions as to the role channels should play, synergies between channels and optimal combinations of channels. The nature of the content encountered in those touchpoints and the degree to which that content stimulates customer interaction, appear key to the overall customer experience. This raises questions regarding the nature of channels and customisation of content for specific channels.

As noted above, the journey repository is a novel element and offers potential to support cross-channel integration, omnichannel management and customer experience management. We encourage research into approaches for realising that potential.

The idea of applying "gamification" to encourage customer interaction also appears to have strong potential. We have not covered this topic and would welcome more research as it is widely used as a tool to engage customers to buy products and services.

We believe further insights into the relationship between customer experience, customer engagement and brand performance could be obtained through an interdisciplinary approach encompassing psychology, behavioural economics, marketing and computer science among others.

We hope our framework stimulates future collaborative research and cross-fertilisation across the fields of digital marketing, social CRM, omnichannel CRM and customer experience/engagement.

\section{References}

Acker, O.; Gröne, F.; Akkad, F.; Pötscher, F. and Yazbek, R. (2011). Social CRM: How companies can link into the social web of consumers. In: Journal of Direct, Data and Digital Marketing Practice,13, 3-10.

Ajmera, J.; Ahn, H.; Nagarajan, M.; Verma, A.; Dill, S.; Denesuk, M. (2013). A CRM system for Social Media. WWW '13: 22nd International World Wide Web Conference, Rio de Janeiro, Brazil, May, 2013.

Alexander, M. and Jaakkola, E. (2015). Customer Engagement Behaviours and Value Cocreation. Chapter within "Customer Engagement: Contemporary Issues and Challenges", May 2015. 
Alves, H.; Fernandes, C.; Raposo, M. (2016). Social Media Marketing: A Literature Review and Implications. Psychology \& Marketing, Vol. 33(12): 1029-1038 (December 2016)

Appel, G.; Grewal, L.; Hadi, R; Stephen, A.T. (2020). The future of social media in marketing. Journal of the Academy of Marketing Science (2020) 48:79-95.

Bart, Y.; Stephen, A.T.; and Sarvary, M. (2014). Which Products Are Best Suited to Mobile Advertising? A Field Study of Mobile Display Advertising Effects on Consumer Attitudes and Intentions. Journal of Marketing Research, 51 (June), 270-85.

Bone, S.A., Fombelle, P.W., Ray, K.R., and Lemon, K.N. (2015). “How Customer Participation in B2B Peer-to-Peer Problem-Solving Communities Influences the Need for Traditional Customer Service”, Journal of Service Research, 18 (1), 2015, pp. $23-38$.

Bowden, J.L.H. (2009). The process of customer engagement: A conceptual framework. Journal of Marketing Theory and Practice 17(1): 63-74.

Brakus, J. J., Schmitt, B. H., \& Zarantonello, L. (2009). Brand Experience: What Is It? How Is It Measured? Does It Affect Loyalty? Journal of Marketing, 73(3), 52-68.

Brodie, R. J., Hollebeek, L. D., Jurić, B., \& Ilić, A. (2011). Customer Engagement: Conceptual Domain, Fundamental Propositions, and Implications for Research. Journal of Service Research, 14(3), 252-271.

Brodie, R. J., \& Hollebeek, L. D. (2011). Advancing and Consolidating Knowledge About Customer Engagement. Journal of Service Research, 14(3), 283-284.

Brodie, R. J., Ilic, A., Juric, B., \& Hollebeek, L. (2013). Consumer engagement in a virtual brand community: An exploratory analysis. Journal of Business Research, 66(1), 105-114.

Bronner, F. and de Hoog, R. (2010). Consumer-generated versus marketer-generated websites in consumer decision making. International Journal of Market Research, Vol. 52, No. 2, pp.231-248.

Brynjolfsson, Erik, Yu Jeffrey Hu, and Mohammed S. Rahman. (2013). Competing in the Age of Omnichannel Retailing. MIT Sloan Management Review, 54 (4), 23-29.

Bucko, J., Kakalejčík, L. and Ferencová, M. (2018). Online shopping: Factors that affect consumer purchasing behaviour, Cogent Business and Management, 5:1, 1535751.

Burmann, C. (2010) A call for user-generated branding. Journal of Brand Management, 18(1), pp. 1-4. 
Calder, B. J., Hollebeek, L. D., and Malthouse, E. C. (2018). Creating stronger brands through consumer experience and engagement. In R. W. Palmatier, V. Kumar, and C. M. Harmeling (Eds.). Customer engagement marketing (pp. 221-242). Cham, Switzerland.

Calder, B.J., Malthouse, E.C. \& Schaedel, U. (2009) An experimental study of the relationship between online engagement and advertising effectiveness. Journal of Interactive Marketing, 23(4), pp. 321-331.

Calder, B. J., Isaac, M. S.; Malthouse, E. C. (2013). Taking the Customer's Point-of-View, Marketing Science Institute Working Paper Series Report, \#13-102.

Calder, B.J.; Isaac, M.S.; Malthouse, E.C. (2016). How to Capture Consumer Experiences: A Context-Specific Approach to Measuring Engagement. Journal of Advertising Research, Mar 2016, 56 (1) 39-52; DOI: 10.2501/JAR-2015-028

Calder, B. J., Hollebeek, L. D., and Malthouse, E. C. (2018). Creating stronger brands through consumer experience and engagement. In R. W. Palmatier, V. Kumar, and C. M. Harmeling (Eds.). Customer engagement marketing (pp. 221-242). Cham, Switzerland.

Cao, L. and Li, L. (2015). The Impact of Cross-Channel Integration on Retailers' Sales Growth, Journal of Retailing, Volume 91, Issue 2, pp.198-216

Carlson, J., Rahman, M., Voola, R., \& De Vries, N. (2018). Customer engagement behaviours in social media: Capturing innovation opportunities. Journal of Services Marketing, 32(1), 83-94.

Carlson, J., Gudergan, C., Gelhard, C., \& Rahman, M. M. (2019). Customer engagement with brands in social media platforms: Configuration, equifinality and sharing. European Journal of Marketing, 53(9), 1733-1758.

Cattrall, D. (2016). The data warehouse feedback interface. BI Journal, September 2016, TDWI, TDWI.org.

Cattrall, D. (2017). Building the single customer view in the data warehouse. BI Journal, December 2017, TDWI, TDWI.org.

Cetină, I.; Munthiu, M.-C.; Rădulescu, V. (2012). Psychological and Social Factors that Influence Online Consumer Behavior. Procedia - Social and Behavioral Sciences, Vol 62, Page 184-188.

Chaffey, D. and Ellis-Chadwick, F. (2016). Digital Marketing. Sixth Edition. Pearson. 
Chan, T; Zheng, X.; Cheung, C.; Lee, M; Le, Z. (2014). Antecedents and consequences of customer engagement in online brand communities. Journal of Marketing Analytics, June 2014.

Chang, Y.; Li1 Y.; Yan, J. \& Kumar, V. (2019). Getting more likes: the impact of narrative person and brand image on customer-brand interactions. Journal of the Academy of Marketing Science (2019) 47:1027-1045.

Cheung, C.M.K., Lee, M.K.O. and Jin, X.L. (2011). Customer engagement in an online social platform: A conceptual model and scale development. International Conference on Information Systems 2011, Shanghai, China.

Choudhury, Musfiq; Harrigan, Paul. (2014). CRM to social CRM: the integration of new technologies into customer relationship management. Journal of Strategic Marketing, 2014.

De Keyser, A., Lemon, K. N., Klaus, P., \& Keiningham, T. L. (2015). A Framework for Understanding and Managing the Customer Experience. Marketing Science Institute Working Paper Series Report, \#15-21.

de Vries, L., Gensler, S., and Leeflang, P.S.H. (2012). Popularity of Brand Posts on Brand Fan Pages: An Investigation of the Effects of Social Media Marketing, Journal of Interactive Marketing, 26 (2), 2012, pp. 83-91.

Dwivedi, Y.K.; Ismagilova, E.; Hughes, L.D.; Carlson, J.; Filieri, R.; Jacobson, J.; Jain, V.; Karjaluoto, H.; Kefi, H.; Krishen, A.S.; Kumar, V. Rahman, M.M.; Raman, R.; Rauschnabel, P.A.; Rowley, J.; Salop, J.; Tran, G.A. and Wang, Y. (2020). Setting the future of digital and social media marketing research: Perspectives and research propositions. International Journal of Information Management, July 2020.

Edelman, David C. (2010), “Branding in the Digital Age,” Harvard Business Review, 88 (12), $62-69$.

Edelman, David C. and Marc Singer (2015), "Competing on Customer Journeys," Harvard Business Review, 93 (November), 88-100.

Fatma, Saba (2014). Antecedents and Consequences of Customer Experience Management A Literature Review and Research Agenda. International Journal of Business and Commerce Vol. 3, No.6: Feb 2014 [32-49]

Gensler, S., Völckner, F., Liu-Thompkins, Y., and Wiertz, C. (2013). Managing Brands in the Social Media Environment. Journal of Interactive Marketing, 27 (4), 2013, pp. 242-256. 
Geurina, A.N.; Burch, L.M. (2017). User-generated branding via social media: An examination of six running brands. Sport Management Review, 20 (2017) 273-284

Greenberg, P. (2010). CRM at the Speed of Light. Fourth Edition.

Hasanata, M.W.; Hoqueb, A; Hamid, A.B.A. (2019). Effect of Customer Relationship Management in Digital Marketing for Customer Satisfaction and Loyalty. International Conference on Business, Accounting, Finance and Economics (BAFE, 2019), Universiti Tunku Abdul Rahman, Kampar, Perak, Malaysia, 4th Oct, 2019.

Hennig-Thurau, T., Gwinner, K. P.,Walsh, G., and Gremler, D. D. (2004). Electronic wordof-mouth via consumer-opinion platforms: What motivates consumers to articulate themselves on the internet? Journal of Interactive Marketing, 18(1), 38-52.

Hennig-Thurau, T., Malthouse, E. C., Friege, C., Gensler, S., Lobschat, L., Rangaswamy, A. and Skiera, B. (2010). The Impact of New Media on Customer Relationships, Journal of Service Research, 2010 13: 311, DOI: 10.1177/1094670510375460

Hennig-Thurau, T., Hofacker, C.F., and Bloching, B. (2013). Marketing the Pinball Way: Understanding How Social Media Change the Generation of Value for Consumers and Companies. Journal of Interactive Marketing, 27 (4), 2013, pp. 237-241.

Hewett, Kelly; Rand, William; Van Heerde, Harald. (2016). Brand Buzz in the Echoverse. Journal of Marketing, 80 (3), 1-24.

Hollebeek, L.D. (2011): Demystifying customer brand engagement: Exploring the loyalty nexus, Journal of Marketing Management, 27:7-8, 785-807.

Hollebeek, L. D., Glynn, M. S., \& Brodie, R. J. (2014). Consumer brand engagement in social media: Conceptualization, scale development and validation. Journal of Interactive marketing, 28(2), 149-165.

Hollebeek, L.D., Srivastava, R. K., \& Chen, T. (2019). S-D Logic-Informed Customer Engagement: Integrative Framework, Revised Fundamental Propositions, and Application to CRM. Journal of the Academy of Marketing Science. 47, pages161-185 (2019).

Holliman, G., and Rowley, J. (2014). Business to business digital content marketing: Marketers' perceptions of best practice. Journal of Research in Interactive Marketing, 8(4), 269-293.

Homburg, C., Jozié, D., \& Kuehnl, C. (2017). Customer Experience Management: Toward Implementing an Evolving Marketing Concept. Journal of Academy of Marketing Science, $45,377-401$. 
Hui, Sam K., Jeffrey J. Inman, Yanliu Huang, and Jacob Suher. (2013). The Effect of In-Store Travel Distance on Unplanned Spending: Applications to Mobile Promotion Strategies. Journal of Marketing, 77 (March), 1-16.

Jaakkola, E., and Alexander, M. (2014). The role of customer engagement behaviour in value co-creation: a service system perspective. Journal of Service Research, 17(3), 247-261.

Jayasingh, S. (2019). Consumer brand engagement in social networking sites and its effect on brand loyalty, Cogent Business \& Management, 6:1, 1698793

Järvinen, J., and Taiminen, H. (2016). Harnessing marketing automation for B2B content marketing. Industrial Marketing Management, 54, 164-175.

Kannan, P.K. and Li, H. L. (2017). Digital marketing: A framework, review and research agenda, International Journal of Research in Marketing, 34, 22-45.

Kaplan, A.M. and Haenlein, M. (2010). Users of the world, unite! The challenges and opportunities of social media. Business Horizons, Vol. 53, No. 1, pp.59-68.

Kapoor, K. K., Tamilmani, K., Rana, N. P., Patil, P., Dwivedi, Y. K., \& Nerur, S. (2018). Advances in social media research: Past, present and future. Information Systems Frontiers, 20(3), 531-558.

Karjaluoto, H., Mustonen, N., and Ulkuniemi, P. (2015). The role of digital channels in industrial marketing communications. Journal of Business and Industrial Marketing, 30(6), 703-710.

Kaur, P., Dhir, A., Rajala, R., \& Dwivedi, Y. (2018). Why people use online social media brand communities: A consumption value theory perspective. Online Information Review, 42(2), 205-221.

Kimmel, A.J. and Kitchen, P.J. (2014). WOM and social media: presaging future directions for research and practice. Journal of Marketing Communications, Vol. 20, Nos. 1-2, pp.5-20.

Klaus, P., \& Maklan, S. (2011). Towards a better measure of customer experience. International Journal of Market Research, 55(2), 227-246.

Kumar, V. \& Pansari, A. (2015). Competitive advantage through engagement. Journal of Marketing Research, Volume: 53 issue: 4, page(s): 497-514, DOI:

http://dx.doi.org/10.1509/jmr.15.0044.

Kotler, P., Kartajaya, H., Setiawan, I. (2017) Marketing 4.0, Moving from traditional to digital. Wiley. 
Kubina, Milan; Lendel, Viliam. (2015). Successful Application of Social CRM in The Company. Procedia Economics and Finance, 23 (2015) 1190 - 1194

Kumar, A., Bezawada, R., Rishika, R., Janakiraman, R., Kannan, P.K. (2016) From Social to Sale: The Effects of Firm-Generated Content in Social Media on Customer Behavior, Journal of Marketing.

Kumar, V.; Aksoy, L.; Donkers, B.; Venkatesan, Rajkumar; Wiesel, T.; Tillmanns, S. (2010). Undervalued or Overvalued Customers: Capturing Total Customer Engagement Value. Journal of Service Research 13(3) 297-310.

Lee, D., Hosanagar, K., \& Nair, H. S. (2018). Advertising content and consumer engagement on social media: evidence from Facebook. Management Science, 64, 5105-5131. https://doi.org/10.1287/mnsc.2017.2902.

Leek, S., Canning, L., and Houghton, D. (2016). Revisiting the task media fit model in the era of Web 2.0: Twitter use and interaction in the healthcare sector. Industrial Marketing Management, 54, 25-32.

Lemon, K.N and Verhoef, P.C. (2016) Understanding Customer Experience throughout the Customer Journey. Journal of Marketing: AMA/MSI Special Issue, Vol. 80 (November 2016), 69-96.

Li, H. and Kannan, P.K. (2014). Attributing Conversions in a Multi-channel Online Marketing Environment: An Empirical Model and a Field Experiment. Journal of Marketing Research, Vol. LI, 40-56, February 2014.

Lopez, L. J. (2013). Social Media as a way to enhance Customer Service. Copenhagen Business School, 2013, Master's Thesis, Social Sciences in Service Management.

Malthouse, E.C., Haenlein, M., Skiera, B., Wege, E. \& Zhang, M. (2013). Managing customer relationships in the social media era: Introducing the social CRM house. Journal of Interactive Marketing, 27(4), 270-280.

Malthouse, E. C., Calder, B. J., Kim, S. J., \& Vandenbosch, M. (2016a). Evidence That UserGenerated Content That Produces Engagement Increases Purchase Behaviours. Journal of Marketing Management, 32(5), 427-444.

Malthouse, E. C., Calder, B. J., \& Vandenbosch, M. (2016b). Creating Brand Engagement on Digital, Social, and Mobile Media. In R. Brodie, L. Hollebeek, \& J. Conduit (Eds.), Customer Engagement: Contemporary Issues and Challenges (pp. 85-101). London: Routledge. 
Mangold, W. G. and Faulds, D. J. (2009). Social media: The new hybrid element of the promotional mix. Business Horizons, 52(4), 357-365.

Manusama, B.; LeBlanc, N. (2020). Magic quadrant for the CRM customer engagement center, Gartner.

Maslowska, E., Malthouse, E. C., \& Collinger, T. (2016). The Customer Engagement Ecosystem. Journal of Marketing Management, 32(5-6), 469-501.

Meyer, C. and Schwager, A. (2007). Understanding Customer Experience. Harvard Business Review, 85(2), 116-126.

Mollen, Anne and Hugh Wilson (2010). 'Engagement, Telepresence, and Interactivity in Online Consumer Experience: Reconciling Scholastic and Managerial Perspectives. Journal of Business Research, 63 (9/10), 919-925.

MSI (2020), “Research Priorities 2020-2022”. Marketing Science Institute.

[https://www.msi.org/wp-content/uploads/2020/06/MSI_RP20-22.pdf]

Muntinga, D. G., Moorman, M., \& Smit, E. G. (2011). Introducing COBRAs: Exploring motivations for brand-related social media use. International Journal of Advertising, 30(1), $13-46$.

Orenga-Roglá, Sergio and Chalmeta, Ricardo. (2016). Social customer relationship management: taking advantage of Web 2.0 and Big Data technologies. SpringerPlus (2016) $5: 1462$

Ostrom, A., Parasuraman, A., Bowen, D., Patricio, L., Voss, C., \& Lemon, K. (2015). Service research priorities in a rapidly changing context. Journal of Service Research, 18(2), 127159.

Pansari, A. and Kumar, V. (2017). Customer engagement: the construct, antecedents, and consequences. Journal of the Academy of Marketing Science (2017) 45:294-311

Patrício, L., Fisk, R. P., \& Constantine, L. (2011). Multilevel service design: from customer value constellation to service experience blueprinting. Journal of Service Research, 10(4), 318-334.

Patterson, P., Yu, T. and Ruyter, K.D. (2006) Understanding customer engagement in services. Australian and New Zealand Marketing Academy 2006 Conference: Advancing Theory, Maintaining Relevance, 2006, Australia, Brisbane.

Pulizzi, J. (2012). The rise of storytelling as the new marketing. Publishing Research Quarterly, 28, 116-123. 
Pulizzi, J. (2014). Epic Content Marketing: How to Tell a Different Story, Break through the Clutter, and Win More Customers by Marketing Less. McGraw-Hill Education.

Rawson, A.; Duncan, E. and Jones, C. (2013). Touchpoints Matter But It's The Full Customer Journey That Counts. Harvard Business Review, September 2013.

Redding, S. (2015). Can marketing automation be the glue that helps align sales and marketing? Journal of Direct, Data and Digital Marketing Practice, 16(4), 260-265.

Reinhold, Olaf; Alt, Rainer; (2011). Analytical Social CRM: Concept and Tool Support. 24th Bled eConference eFuture: Creating Solutions for the Individual, Organisations and Society June 12 - 15, 2011; Bled, Slovenia

Reinhold, O.; Alt, R. (2012). Social customer relationship management: state of the art and learnings from current projects. Paper presented at the 25th Bled eConference eDependability: Reliable and Trustworthy eStructures, eProcesses, eOperations and eServices for the Future, in Bled, Slovenia. Paper 26. 155-169.

Rigby, Dan (2011). The Future of Shopping. Harvard Business Review, 89(12), 65-76.

Rossmann, A.; Wilke, T.; Stei, G. (2017). Usage of Social Media Systems in Customer Service Strategies. Proceedings of the 50th Hawaii International Conference on System Sciences.

Sahni, N. S., Wheeler, S. C., \& Chintagunta, P. (2018). Personalization in email marketing: The role of non-informative advertising content. Marketing Science, 37(2), 236-258.

Schau, H. J., Muñiz Jr, A. M., \& Arnould, E. J. (2009). How brand community practices create value. Journal of Marketing, 73(5), 30-51.

Stefan Willi, H.; Gamal, K. (2012). Social Customer Relationship Management - From Customer to Friend. European, Mediterranean and Middle Eastern Conference on Information Systems 2012

Stewart, M. C. and Arnold, C. L. (2016) Defining Social Listening: Recognizing an emerging dimension of listening. Proceedings from Florida Communication Association's 86th Annual Convention. Orlando, FL.

Stewart, Margaret C.; Atilano, Maria; Arnold, Christa L. (2017). Improving Customer Relations with Social Listening: A Case Study of an American Academic Library. International Journal of Customer Relationship Marketing and Management, Volume 8 , Issue 1 , January-March 2017 
Su Jung Kim; Wang, Rebecca Jen-Hui; Malthouse, Edward C. (2015). The Effects of Adopting and Using a Brand's Mobile Application on Customers' Subsequent Purchase Behavior. Journal of Interactive Marketing, 31 (2015) 28-41

Swaminathan, V., Sorescu, A., Steenkamp, J-B., Clayton, T., O’Guinn, G., Schmitt, B. (2020). Branding in a Hyperconnected World: Refocusing Theories and Rethinking Boundaries, Journal of Marketing, vol 84(2) 24-26

Swani, K., Brown, B. P., and Milne, G. R. (2014). Should tweets differ for B2B and B2C? An analysis of Fortune 500 companies' Twitter communications. Industrial Marketing Management, 43(5), 873-881.

Swani, K., Milne, G., and Brown, B. P. (2013). Spreading the word through likes on Facebook: Evaluating the message strategy effectiveness of Fortune 500 companies. Journal of Research in Interactive Marketing, 7(4), 269-294.

Swani, K., Milne, G. R., Brown, B. P., Assaf, A. G., and Donthu, N. (2017). What messages to post? Evaluating the popularity of social media communications in business versus consumer markets. Industrial Marketing Management, 62, 77-87.

Świeczak, W. (2013). Marketing Automation Processes as a Way to Improve Contemporary Marketing of a Company. Marketing of Scientific and Research Organizations. September 2013.

Valos, M. J., Turner, P., Scheepers, H., and Stockdale, R. (2015). Integrating online communities within business-to-business marketing communications: an exploratory study. Journal of Marketing Communications, 1-19.

van Doorn, J.; Lemon, K.N.; Mittal, V; Nass, S.; Pick, D.; Pirner, P.; Verhoef, P. (2010). Customer Engagement Behavior: Theoretical Foundations and Research Directions. Journal of Service Research, 13 (3), 253-66.

Verhoef, Peter C.; Lemon, Katherine N.; Parasuraman, A.; Roggeveen, Anne; Tsiros, Michael; Schlesinger, Leonard A. (2009). Customer Experience Creation: Determinants, Dynamics, and Management Strategies. Journal of Retailing, 85 (1), 31-41.

Verhoef, Peter C.; Kannan, P.K.; Inman, J. Jeffrey. (2015). From Multi-Channel Retailing to Omni-Channel Retailing Introduction to the Special Issue on Multi-Channel Retailing. Journal of Retailing.

Vivek, Shiri, Sharon E. Beatty, and Robert Morgan (2012), "Customer Engagement: Exploring Customer Relationships Beyond Purchase,” Journal of Marketing Theory \& Practice, 20, 2, 122-46. 
Voramontri, D.; Klieb, L. (2018). Impact of Social Media on Consumer Behaviour.

International Journal of Information and Decision Sciences. July 2018

Wang, Rebecca Jen-Hui, Edward C. Malthouse, and Lakshman Krishnamurthi (2015). On the Go: How Mobile Shopping Affects Customer Purchase Behavior. Journal of Retailing, 91, 2 , 217-34.

Wang, Rebecca Jen-Hui; Su Jung Kim; Malthouse, Edward C. (2016). Branded Apps and Mobile Platforms as New Tools for Advertising. The New Advertising: Branding, Content, and Consumer Relationships in the Data-driven Social Media Era, Ruth E. Brown, Valerie K. Jones, Ming Wang, editors. Santa Barbara, CA: ABC-CLIO.

Wang, W. L., Malthouse, E. C., Calder, B., \& Uzunoglu, E. (2019). B2b content marketing for professional services: In-person versus digital contacts. Industrial Marketing Management 81 (2019) 160-168.

Wereda, Wioletta; Grzybowska, Monika. (2016). Customer Experience - Does it Matter? Modern Management Review (MMR), vol. XXI, 23 (3/2016), pp. 199-207.

Wittwer, Matthias; Reinhold, Olaf; Alt, Rainer. (2017). Customer Context and Social CRM: A Literature Review and Research Agenda. BLED 2017 Proceedings. 3.

Xu, Jiao, Chris Forman, Jun B. Kim and Koert Van Ittersum (2014). News Media Channels: Complements or Substitutes? Evidence From Mobile Phone Usage, Journal of Marketing, 78 (4), 97-112.

Yogesh, F; Yesha, M. (2014). Effect of social media on purchase decision. Pacific Business Review International, Volume 6, Issue 11. 